Georgia State University

ScholarWorks @ Georgia State University

$4-1-2012$

\title{
Immigrant Employment through the Great Recession: Individual Characteristics and Metropolitan Contexts
}

\author{
Cathy Yang Liu \\ Georgia State University, cyliu@gsu.edu \\ Jason Edwards \\ Georgia State University, jedwards50@gsu.edu
}

Follow this and additional works at: https://scholarworks.gsu.edu/uwrg_workingpapers

\section{Recommended Citation}

Liu, Cathy Yang and Edwards, Jason, "Immigrant Employment through the Great Recession: Individual Characteristics and Metropolitan Contexts" (2012). UWRG Working Papers. 52.

https://scholarworks.gsu.edu/uwrg_workingpapers/52

This Article is brought to you for free and open access by the Usery Workplace Research Group at ScholarWorks @ Georgia State University. It has been accepted for inclusion in UWRG Working Papers by an authorized administrator of ScholarWorks @ Georgia State University. For more information, please contact scholarworks@gsu.edu. 
Working Paper 2012-4-1

April 2012

\section{Immigrant Employment} through the Great Recession: Individual Characteristics and Metropolitan Contexts

Cathy Yang Liu

Georgia State University

Jason Edwards

Georgia State University 


\title{
Immigrant Employment through the Great Recession: Individual Characteristics and Metropolitan Contexts
}

\author{
Cathy Yang Liu ${ }^{1}$ cyliu@gsu.edu \\ Jason Edwards jedwards50@gsu.edu \\ Andrew Young School of Policy Studies \\ Georgia State University
}

April 2012

\begin{abstract}
Immigrants continue to settle in metropolitan areas across the United States and bring significant changes to various urban labor markets. The current Great Recession which officially started in December 2007 and ended in June 2009 (National Bureau of Economic Research, 2010) further intensified the debate on immigration. It is important to understand how immigrants fared through this economic downturn and their evolving employment patterns within a diversity of metropolitan areas. Using American Community Survey (ACS) data for 2007 and 2009, this paper traces the employment outcomes of immigrants compared to nativeborn workers before and after the recession across the 100 largest metropolitan areas.

Distinctions are made between Asian immigrants and Latino immigrants. Regression analysis further tests the effect of individual human capital characteristics and metropolitan economic, demographic, and policy contexts on immigrant's likelihood of securing employment during this time period.
\end{abstract}

\footnotetext{
${ }^{1}$ This research is supported by Upjohn Institute of Employment Research.
} 


\section{INTRODUCTION}

Immigrants continue to settle in metropolitan areas across the United States and bring significant changes to various urban labor markets. There exists heated debate regarding immigrant labor market outcomes and immigrants' impact on native-born workers with comparable skills (Borjas, 1987, 1999, 2003; LaLond and Topel, 1991; Orrenius and Zavodny 2007; Bohn 2010). The current Great Recession, which started in December 2007 and ended in June 2009 (National Bureau of Economic Research, 2010), further intensified the debate on immigration and relative outcomes of immigrants (Kochhar, Espinoza, and Hinze-Pifer 2010; Pollin and Wicks-Lim 2011). Much of the public discourse centers on the rise in national unemployment rate from $4.9 \%$ in 2007 to $9.7 \%$ in 2009 - it's highest level since 1983 (Sahin, Song and Hobijn 2009)- yet little is revealed about the employment prospects of immigrants during this rough economic period. It is important to understand immigrant outcomes as a result of this economic downturn and their evolving employment patterns in diverse metropolitan areas. Understanding immigrant employment dynamics can inform policies that target assistance to immigrants and their families as well as help the communities that these immigrants populate.

Economic recessions harm employment prospects and raise unemployment in general, but the effects are not even across different groups and metropolitan areas. Existing theoretical perspectives and evidence on immigrant employment offer mixed insights regarding the economic trajectories of immigrants in an economic recession. On the one hand, minorities and immigrants are more likely than the native-born workers to engage in various forms of contingent and flexible employment, such as independent contractors, temporary help workers, day laborers, on-call workers, and contract firm employees (von Hippel, et al, 2006). If it is true that contingent workers are more vulnerable to economic shocks than traditional workers (Peck 
and Theodore, 2007), it might be the case that immigrants experience greater job losses during the recession. Coupled with work authorization status, their job security can be even worse. On the other hand, immigrants are locationally and occupationally mobile (Borjas, 2001). Given their loose spatial attachment to the host country, they tend to follow economic opportunities in their residential choices. They are more likely to accept jobs with sub-standard remuneration and conditions and tolerate pay penalties (Catanzarite, 2002; author, 2011). The fact that they are not entitled to unemployment benefits might also push immigrants to consider a wider spectrum of jobs. If these hold true, we can expect that unemployment remains low for immigrants through the recession, though underemployment might rise.

An emerging body of research has examined the changing settlement patterns of immigrants from established gateway metropolitan areas to new and emerging gateways (Singer, 2004; Lichter and Johnson, 2009; Painter and Yu, 2010). Given the different size and composition of the urban economy, as well as the strength of ethnic networks provided by immigrant population, it can be expected that how economic shocks are absorbed among immigrant workers in these labor markets would vary. Singer and Wilson (2010) examined the effect of the Great Recession on immigrant settlement patterns across metropolitan areas and distinguished between those that have "weathered" the recession and those that experienced growth reversal. Recent evidence suggests that immigrants in smaller metropolitan areas are faring better than their counterparts in gateway metropolitan areas (Gurak and Kritz, 2000; Hall, 2009), possibly due to less intense competition within the immigrant labor force in those cities. But research on the housing market did not identify any advantage in achieving homeownership for immigrants living in mid-size metropolitan areas as compared to those living in larger established gateways (Painter and $\mathrm{Yu}, 2010)$. It is not clear whether the intra-immigrant group 
competition effect will outweigh the positive network effect of immigrant concentration and how different types of immigrant gateways will absorb the economic shock on immigrant employment during the recession.

This research will address the Great Recession's impact on immigrants' employment patterns by placing special emphasis on how the metropolitan economic and social context plays a role in shaping outcomes for immigrants. Complicating the issue is the fact that states across the country enacted a series of immigration-related laws around the same period. These laws restrict hiring unauthorized immigrant workers through E-Verify systems and lower immigrant inflow and limit employment opportunities for unauthorized immigrants (Lofstrom, Bohn and Raphael, 2011). However, they might have an impact on the employment prospects of others as well. Thus, this policy environment as a state contextual variable is taken into consideration in this analysis.

This research answers these questions using American Community Survey (ACS) microdata for the years 2007 and 2009. These two observation years capture the before- and after-recession periods fairly well. We restrict our analysis to the top 100 out of all metropolitan areas so as to isolate effects for the major immigrant destinations. First, general trends in terms of immigrant presence and immigrant growth between 2005 and 2009 in each MSA are documented and a typology is developed to categorize different types of immigrant-receiving metropolitan areas. Then, we conduct empirical analysis to gauge the individual and metropolitan characteristics that play a role in immigrants' employment outcomes through the recession, in comparison to the native-born population. We also make a distinction between lowskilled and high-skilled immigrants, as well as between Asian and Latino immigrants. 


\section{LITERATURE REVIEW}

\section{Immigrant Employment and Recession}

While previous research demonstrates the pro-cyclical nature of immigrant economic outcomes, we know little about whether and how immigrant workers differ from the native-born workers in terms of employment determinants during one of the greatest economic downturns in U.S. history. Studies on immigrants' employment status and earnings in the labor market are prolific and generally find that immigrants feature relatively high employment rate and mobility compared to native-born workers (Aponte, 1996; Borjas, 2001). Immigrants' economic fortunes are tied to their skill set, including education, English proficiency and work-related experiences (Sanders and Nee 1996; Chiswick 1999; Akresh 2007; Chiswick and Miller 2008). As immigrants stay in the host country for a longer period of time and assimilate economically and culturally, their employment trajectories improve (Myers, 1999). Immigrants tend to heavily cluster on both ends of the skill spectrum and generate distinctive ethnic niches, industries or occupations with considerable immigrant concentration (Waldinger, 1994; Waldinger and DerMartirosian, 2001). Yet, immigrants' skill levels are not even across metropolitan areas, which are determined by their migration history, economic structure, proximity to immigrants' home countries, and social networks (Hall et al, 2011).

The Great Recession brought the country to an economic halt. It slowed immigration inflow (Passel and Cohn, 2010) and forced immigrant and native-born workers alike into joblessness and poverty. It is an open question however as to how the economic downturn hit immigrants differently than their native-born counterparts. On the one hand, some find that immigrants' employment patterns are more volatile and cyclical over business cycles due to their relative youth, average low skill level, and concentration in cyclically sensitive industries and 
occupations as evidenced during the 2001 recession and recovery (Orrenius and Zavodny 2009). Orrenius and Zavodny found that immigrant employment and unemployment rates exhibit greater cyclicality than the native-born with the same skill levels, particularly the low-skilled segment of the workforce and those in construction, services and hospitality sectors. The early period of the economic recovery in 2010 saw immigrant workers gain jobs while the native-born lose jobs (Kochhar, Espinoza and Hinze-Pifer, 2010).

On the other hand, immigrants may be more flexible and able to move across regions, industries, and occupations in search of jobs (Borjas 2001). Given their relatively loose spatial attachment to the host country, they tend to follow economic opportunities in their residential choices. Immigrants are more likely to accept jobs with sub-standard remuneration and conditions that result in pay penalties (Catanzarite, 2002; author, 2011). Along with the slowing of immigration inflow during the recession might have come reduced competition for jobs traditionally held by immigrants. If these conditions hold true, we can expect that unemployment remains low for immigrants through the recession, though underemployment, might rise. Regardless, those with low skills, limited English proficiency and few job channels and social connectedness are expected to be at greater risk of unemployment.

\section{Immigrant Settlement Pattern and Metropolitan Context}

An increasing body of research has examined the changing settlement patterns of immigrants away from established gateway metropolitan areas to new and emerging gateways (Singer, 2004; Massey, 2008; Lichter and Johnson, 2009; Painter and Yu, 2010; Wilson and Singer, 2011). We expect that how immigrants respond to economic shocks varies given the different size and composition of urban economies, general economic barriers to entry into the 
labor market, as well as the strength of ethnic networks provided by immigrant populations. In addition, metropolitan characteristics and contexts play an important role in immigrant migration patterns (Baird et al, 2008; Winger and Wilson, 2010), housing markets (Painter and Yu, 2010), and self-employment (Wang, 2010).

Contexts of reception refer to the economic, social and institutional framework of the areas in which immigrants settle (Portes \& Rumbaut, 1996). Immigrants enter into local labor markets with different industrial structures, settle in communities with various densities of ethnic networks, and face contrasting policy and institutional environments. These place-based contextual factors interact with immigrants' individual human capital attributes to determine their employment prospects and earning potential (Portes \& Bach, 1985; Reitz, 1998; Ellis, 2001). Previous research found that ethnic clustering decreases in destinations with a longer immigration history and a larger immigrant presence, which allows for the participation of immigrants in a wider spectrum of industries (author, 2011). New gateways, those metropolitan areas that have attracted a large number of recent immigrants and feature a higher level of ethnic clustering in the labor market, might be more vulnerable to national economic shocks.

High presence of immigrants, with dense social networks, might facilitate the job search process of immigrants and provide more opportunities in immigrant-owned businesses; however, they might also create higher competition for jobs given that immigrants with similar skill sets are more likely to act as substitutes for themselves (Peri and Sparber, 2009; author, 2012). This negative competition effect could outweigh the benefits of ethnic networks, however, as immigrants might be "deflected" by the saturated economic opportunities and unwelcoming environment in established gateways (Light, 2006). Recent evidence suggests that immigrants in metropolitan areas with smaller immigrant populations are faring better in the labor market in 
terms of employment and earnings than their counterparts in traditional gateway metropolitan areas (Gurak and Kritz, 2000; Hall, 2009), possibly due to less intense competition among the immigrant population in those cities. The same does not apply to the housing market, as immigrants settling in smaller metropolitan areas are no more successful than their counterparts in gateway metropolitan areas (Painter and Yu 2010). Thus, immigrant gateway type, as measured by both the presence of immigrant and the relative recency of immigrant population is an important MSA-level consideration.

Coinciding with the recession, state legislatures passed 346 immigration-related pieces of legislation and enacted 27 laws related to the employment of immigrants in 2010 alone (Lofstrom, Bohn and Raphael, 2011). Many of the state policies include mandating employers to use E-Verify, a national work authorization verification system to curtail the hiring of unauthorized immigrant workers. As of 2007, three states placed into effect E-Verify or similar employment eligibility verification systems, with that number growing to 10 by 2009 and 19 (enacted or under consideration) by early 2012 (LawLogix 2012). A complete list of E-Verify states and corresponding adoption years is provided in Appendix A. One of the first of such policies, the Legal Arizona Workers Act (LAWA) in Arizona, achieved the intended goal of reducing the number of unauthorized immigrants in the state. In the labor market, it restricted their employment opportunities in the formal sector, but pushed some immigrants into selfemployment (Lofstrom, Bohn and Raphael 2011). While public attitudes toward legal and illegal immigrants may in fact be linked (Cowan, Martinez, and Mendiola 1997), these policies might be associated with a number of state-level mechanisms by which the employment prospects of legal immigrants could be hindered as well. 
Since E-Verify is a fairly recent addition to state policy, we consider E-Verify as a state policy signal of the state's attitudes towards unauthorized immigrants that do not change in the short term (see Ryu, Bowling, Chao, and Wright 2008 for further demonstration of exogenous state policy context). De Jong and Steinmetz (2004) found a positive effect of immigrant receptivity attitudes of citizens on the labor market attainment of immigrants and more general political science research establishes a connection between public attitudes and policy adoption (e.g., Burstein 1998; Lax and Phillips 2009). Thus, where E-Verify is adopted we expect lower general receptivity to immigrants, particularly given that E-Verify policies do lead to, for example, greater false employment rejections for Latinos and African Americans than for Whites (Pearson-Merkowitz 2011).

\section{DATA AND METHODOLOGY}

\section{Data and Context}

This research makes use of American Community Survey (ACS) microdata for years 2005, 2007, and 2009 to explore immigrants' labor market outcomes before and after the 20072009 recession. Data are obtained from the Minnesota Population Center Integrated Public Use Microdata Series (IPUMS) (Ruggles et al. 2010). We include the top 100 Metropolitan Statistical Areas (MSA) as determined by total population for year 2009 in the analysis. A key advantage of IPUMS data is that its MSA boundary definitions utilizing Public Use Microdata Areas (PUMA) are consistent from 2000 onward. Since both our individual-level and MSAlevel variables are drawn from IPUMS, we maintain comparability in our units of analysis throughout the study period.

[Table 1 about here] 
An overview of the growth of the total population, immigrants in general, and Asian and Latino immigrants in particular is provided in Table 1 for 2005, 2007, and 2009. We include 2005 data here to provide a longer perspective for the changes during the 2007-2009 Great Recession. Comparisons are also made between the combined 100 MSA sample and the entire national 283 MSAs to provide the context of our study. Through all these three years, the 100 MSA sample makes up about 63 percent of the total U.S. population, while hosting around 84 percent of the immigrant population. The study sample of Asian immigrants and Latino immigrants also comprises an overwhelming majority of their national populations, at roughly 88 percent and 83 percent respectively. As a group, immigrants make up a slightly larger percentage of the sample population (approximately 17 percent) than the U.S. population (12 percent). There also exists a slow-down of immigrant growth during the recession, with immigrants growing by between 5.4 percent (100 MSAs) and 6.2 percent (U.S.) from 2005 to 2007 compared to only between 1.0 percent (100 MSAs) and 1.3 percent (U.S) between 2007 and 2009.

[Table 2 about here]

Table 2 presents the unemployment rates for the same population and immigrant groups from 2005 to 2009. The unemployment rates for the 100 MSA sample and the whole U.S. resemble each other quite closely in most cases, with the exception of Latino immigrants. Latino immigrants' unemployment rate is higher in all years in the MSA sample than the U.S. as a whole. Comparing unemployment rates across groups for each year, in all three years Asian immigrants have the lowest unemployment rate while Latino immigrants have the highest. The native-born population closely resembles the unemployment rate (both for the $100 \mathrm{MSA}$ sample and the U.S.) for the total population for each of the three study years. Before (2005 and 2007) 
and after (2009) the recession changes in unemployment reveal dramatic rises in unemployment rates for all groups from 2007 to 2009, with slight to moderate declines in unemployment between 2005 and 2007. The difference between the 2005/07 and 2007/09 comparisons reveals changes in employment fortunes during the recession that differ from the change in employment during a similar duration but immediately prior period. When immigrants are further broken down by their skill level, it is apparent that the low-skilled immigrants (less than a high-school degree) are the hardest hit by the recession, followed by medium-skilled immigrants (less than a college degree), as compared to high-skilled immigrants (college degree and above).

\section{Methodology and Variables}

Variables used in this analysis are drawn from the ACS and describe individual- and MSA-level characteristics during the years 2005, 2007, and 2009. Since the dependent variable is a dichotomous measure of individual employment or unemployment, a probit regression model is used. Probit results are interpreted with a dependent variable that is an unmeasured variable, $\mathrm{Z}$, determined by coefficients on the independent variables that represent a change in the cumulative normal probability due to a one-unit change in the independent variable. Both individual- and MSA-level explanatory variables are entered into the model to examine the effects of individual characteristics and metropolitan contexts on their employment prospects. For this mixed-level analysis, clustered probit (clustered by metropolitan area) with robust standard errors allows us to interpret the results in terms of individual-level factors while controlling for the effect of MSA gateway type, state immigrant receptivity, and local economic size. 
For each population group (all, native-born, immigrants, Asian immigrants and Latino immigrants), the probability of being employed is given by:

$$
\operatorname{Prob}(\text { employed }=1)=\operatorname{probit}\left(\mathrm{x}^{\prime}{ }_{\mathrm{i}} \alpha+\mathrm{y}_{\mathrm{i}}{ } \beta\right)
$$

where Prob is the probability of being employed ( $1=$ employed, $0=$ not employed), $\mathrm{x}_{\mathrm{i}}$ is a vector of individual characteristics, $\alpha$ is a vector of probit parameter estimates for the individual characteristics, $y_{i}$ is a vector of MSA characteristics, and $\beta$ is a vector of probit parameter estimates for the MSA characteristics. For robustness, we run this model using various gateway definitions as determined by the cutoff points for immigrant presence and growth as well as continuous measures of gateway classification.

\section{Individual-level variables}

While much is known about how immigrant characteristics influence employment outcomes during normal economic periods, little is known about immigrants fare during the more cyclical (positive or negative) periods, particularly one as deep as the recent recession. Research suggests that immigrants are more susceptible than natives to macroeconomic fluctuations (Chiswick, Cohen and Zach 1997; Bratsberg, Barth and Raaum 2006) leading us to suspect that immigrants in general fare worse than natives during the recession. As one of the few studies to examine immigrant employment during the Great Recession, Orrenius and Zavodny (2010) support previous findings by demonstrating greater cyclicality for immigrants, particularly among the less-educated.

The question of ethnicity is a key one for this paper. Addressing why Mexican American wages are so low, Trejo (1997) found that lower levels of human capital and younger age as opposed to lower labor market rewards for those characteristics is to blame for ethnic economic 
gaps. The individual-level characteristics in this paper seek to help explain differences in employment outcomes for Latino immigrants and Asian immigrants relative to the native born. Along with race and ethnicity, a number of individual-level factors are known to influence the employment prospects of immigrants, particularly as they fit within the context of ethnic niches (Waldinger 1994). We control for a number of individual-level attributes that might help explain immigrant employment outcomes. Consistent with previous literature, we identify several key personal variables that might influence the likelihood of employment among those in the labor force: gender, marital status, having one or more children, education, English ability, immigration cohort, racelethnicity, and age. Human capital is important to immigrants' fortunes (e.g., Hendricks 2002), with education and English ability standing out among the factors shown to increase wages, employment, and prospects vis-à-vis the business cycle (e.g., Chiswick and Miller, 1992; Hendricks, 2002).

Social networks show a particularly beneficial effect on the wages of Mexican immigrants (Aguilera and Massey 2003) and social connectedness more generally has been shown to be supportive of positive immigrant outcomes (Yoon, Lee, and Goh 2008). Marital status is one important measure of social connectedness (Leighley and Vedlitz 1999). Women and men respond to different social networks and information channels, with benefits oftentimes accruing to male immigrants (Greenwell, Valdez and DaVanzo 1997; Zhou and Logan 1989) and women partially restrained by household responsibilities (Hanson and Pratt 1995). Yet, the recessionary period between 2007 and 2009 reveals a pronounced gender gap in unemployment rate: 10.9 percent for men in August 2009 compared to 8.2 percent for women (Sahin, Song and Hobijn 2010). In addition, the family as social capital tends to augment employment prospects, particularly for the self-employed, with interethnic variation in personal human capital and 
family social capital explanations of differences in employment outcomes (Sanders and Nee 1996). Whereas both natives and immigrants rely on social factors for employment during tough economic times, given the traditionally greater reliance of immigrants on such support networks as ethnic enclaves, we expect marriage to provide additional employment resources to immigrants. The evidence on having children is mixed. While on the one hand, children may lead to cross-class interactions, particularly among certain minorities (Pattillo-McCoy 1999; Jackson 2001), on the other hand, based on research of job-related networks (e.g., Campbell 1988) and negative associations with having children, children may limit network-based employment. Despite the complexity of childcare, we expect having children to have a positive effect on parents' employment, partly due to extended social networks for immigrants.

An important factor to consider in immigrants' economic assimilation and well-being is their period of arrival to the host society and thus duration in the U.S. Assimilation theories suggest that immigrants register socioeconomic progress and cultural familiarity in the host society as their residential tenures increase (Gordon, 1964); though the mode and pace of incorporation can be uneven (Alba, \& Nee, 1997). We expect that one's arrival cohort, a key indicator of assimilation and experience in the local labor market, to be important to an immigrant's economic prospects. Since the 1970s and 1980s were decades of declining wages and unemployment among less-skilled workers, a category in which recently arrived immigrants often found themselves, and considering that immigrants' long-term earnings are comparable to similar native co-ethnics (LaLonde and Topel 1991), we expect these established immigrants to fare better than more recent arrivals. We also expect the most recent arrivals who arrived during the 2000s to be the cohort most negatively affected by the recession.

\section{Metropolitan-Level Variables}


An increasing body of research has examined the changing settlement patterns of immigrants away from established gateway metropolitan areas to new and emerging gateways (Singer, 2004; Massey 2008; Lichter and Johnson, 2009; Painter and Yu, 2010; Wilson and Singer, 2011). While the typologies to describe these emerging gateways differ, they are usually characterized by a high level of recent immigrant arrivals relative to earlier arrivals. Immigrants are argued to weigh economic considerations and employment prospects more than other factors in making their migration decisions, and tend to gravitate towards areas of low barriers to employment and abundant job opportunities (Baird, Adelman, Reid and Jaret 2008). Given that immigrants tend to be the main competitors to comparable immigrant workers (Borjas 1986), we expect immigrant employment outcomes to be worse overall in areas of greater immigrant presence. We also expect that areas where newly arrived immigrants comprise an increasing proportion of the local immigrant population portend better employment prospects for immigrants even during the recession. In other words, while large immigrant populations could indicate either heightened ethnic social network support (positive effect on immigrant employment) or increased competition amongst immigrants (negative effect on immigrant employment), we expect areas in which immigrants are newly emerging to reflect abundant job opportunities for immigrants.

We thus categorize metropolitan areas along these two dimensions, with immigrant presence defined as the percentage of the MSA population who are immigrants in 2007 and immigrant growth defined as the percentage of MSA immigrants in 2007 who arrived in the 10 years prior to 2007 (for similar categorization, see Painter and Yu, 2010). To ensure the robustness of our results, we implement models with various cutoff points for both immigrant growth and immigrant presence (mean and median values for a national set of 283 MSAs and 
mean and median values for the largest 100 MSAs).We describe the model results using median cutoffs for these 100 MSAs in the results section and compare these results with those of the other three models as robustness checks.

Therefore the four categories of MSAs are: 1) high presence and high new arrivals, 2) high presence and low new arrivals, 3) low presence and high new arrivals, and 4) low presence and low new arrivals. "Presence" describes the immigrant proportion of the MSA population in the leading year of a time period comparison. "New arrival" describes the proportion of new arrivals (those arriving within the previous 10 years) of the MSA immigrant population. The primary low/high cutoff for presence is the median of the 100 MSAs (8.47\%) and the primary low/high cutoff for new arrivals is also a median value (41.45\%). For example, a MSA is classified as high presence and high new arrival if at least $8.47 \%$ percent of the MSA population is immigrants and at least $41.45 \%$ percent of the immigrants in that MSA are classified as new arrivals. Detailed MSA groupings are provided in Appendix B. We have 18 MSAs labeled as low presence and low new arrivals, 32 MSAs as low presence and high new arrivals, 32 MSAs as high presence and low new arrivals, and 18 MSAs as high presence and high new arrivals. This categorization captures the latest growth trends of immigrants across MSAs and reflects the relative size and growth of this population.

[Table 3 about here]

Table 3 shows that immigrants comprise the highest percentage of MSA populations in high presence / low new arrivals metropolitan areas while they have the lowest share in both low presence / high new arrivals and low presence / low new arrivals MSAs. The MSA percentage of immigrants who are new arrivals is the lowest (both in 2007 and 2009) in high presence / low new arrivals MSAs. There does appear to be meaningful variation amongst gateway types in 
terms of both measures of immigrant composition. As expected, unemployment rates are higher in 2009 than 2007 for all gateway types and across all population groups given the dramatic cross-cutting national recession. Latino immigrants in high presence / high new arrival gateways show the most dramatic jump in unemployment, going from a low for any gateway type of 4.9 percent in 2007 to a high amongst the four gateway types in 2009 of 10.4 percent. The highest after-recession unemployment rates for Asian immigrants and all immigrants are observed for the high presence gateways as well. This finding supports research suggesting the substitutive nature of immigrants to each other in the labor market. Where immigrants' presence is high, increasing competition amongst immigrants for job opportunities ensues. If it is true that immigrants and native-born workers are not perfect substitutes for each other (Ottaviano and Peri 2007), then native-born workers may benefit at the expense of immigrants in these high presence/high new arrival gateways. Yet, it is also possible that high new arrival gateways are associated with positive employment outcomes for immigrants because they are attractive economic magnets for all workers.

[Table 4 about here]

As we are concerned with how the effect of recession on immigrant employment varies across different metropolitan contexts, we also take into consideration regional variations. Given their distinctive development trajectories and industrial composition, we expect that different regions are hit to various extents through the recession. To capture differences in immigrant populations that may exist across such areas of the country as the Rustbelt and the Sunbelt, we operationalize potential regional historical, cultural, and economic differences as the main Census regions. Table 4 shows the population characteristics and unemployment rates for selected groups by the four regions: Northeast, Midwest, South, and West. The western states, of 
which there are 24, possess immigrants as a larger share of their population in both 2007 and 2009 (23.5 and 22.9 percent respectively) than the other three regions. Of the immigrants in each region, those who are new arrivals (arrived within the previous 10 years) comprise the largest share of the immigrant population in the southern region of the country compared to the other three regions. Unemployment rate rose for all regions between 2007 and 2009 with immigrants faring the best in the Northeast in 2009 at an unemployment rate of 9.2 percent and the worst in the same year in the Midwest (10.9 percent).

In addition, we include two more variables on the MSA level: E-verify status and MSA employment size in 2007. We treat the adoption or eventual adoption of E-Verify requirements as a state contextual variable and a measure of state environment of immigrant receptivity. Given De Jong and Steinmetz's (2004) support for the receptivity thesis and the positive effect of immigrant receptivity attitudes on employment attainment, we hypothesize that state proclivity toward E-Verify adoption captures an important moderator of employment-related attitudes toward unauthorized immigrants with some residual effect on authorized immigrants as well. Metropolitan total employment number is intended to capture the size of the local economy and potential job opportunities.

\section{Descriptive Statistics}

[Table 5 about here]

Table 5 lists the mean statistics of individual- and MSA-level variables for the five samples of comparison: all, all native-born, all immigrants, Asian immigrants, and Latino immigrants. The sociodemographic characteristics show certain variations across the study groups, with a lower percentage of Latino immigrants in the labor force being female and higher 
percentage being low-skilled and medium-skilled. They tend to have a lower average age than the other groups as well. Immigrants in general are more likely to be married and have children than the native-born workers, while a much higher percentage of Asian immigrants speak English than Latino immigrants. Their arrival cohort compositions exhibit much similarity with about a quarter being 2000s arrivals, 31 percent 1990s arrivals, a quarter 1980s arrivals and the rest pre-1980 arrivals.

In terms of MSA-level variables, immigrants as a whole are more concentrated in the South and less concentrated in the Midwest than the native-born population. While around 35 percent of Latino immigrants as well as native-born workers live in the South, only 22 percent of Asian immigrants live there and instead, have a greater presence in the Northeast (22 percent). About 17 percent of Asian immigrants and 26 percent of Latino immigrants live in E-Verify states, as compared to 34 percent of native-born workers. Evidently, immigrants heavily concentrate in high presence gateway metros and gravitate towards MSAs with larger employment bases.

\section{EMPIRICAL RESULTS}

\section{Model Results}

[Table 6 about here]

Regression results for employment likelihood to gauge the effect of both individual characteristics and metropolitan contextual factors throughout the recession period are shown in Table 6. Five separate models are estimated for five population samples: 1) total labor force, 2) all native-born, 3) all immigrants, 4) Asian immigrants, and 5) Latino immigrants. The individual variable results are generally as expected. During the Great Recession period, native- 
born female workers appear to be performing better than male workers but the reverse is true among immigrant workers. Female Latino immigrants are most negatively affected. Those who are married and have children are more likely to be employed; these effects are positive and significant across the board. We consider these two variables as indicators of additional networks one has access to that may provide employment information and/or employment motivation.

Skill, as measured by education level, has consistent and significant impacts on the likelihood of employment. As compared to their high-skilled counterparts, the low-skilled and medium-skilled workers have significantly more difficulty in securing employment. Across the selected sub-groups, the native-born workers showed the largest negative effects for both lowskill and medium-skill, whereas Latino immigrants showed the least negative effects. Immigrants in general are more likely to be employed even during recession period, as demonstrated by the positive and significant sign on the immigrant coefficient in the full sample. This confirms immigrants' overall high employment rate (Aponte, 1996) despite economic downturn. English ability, another measure of human capital, is positively associated with the likelihood of employment. Having English language proficiency opens up opportunities in the formal labor market and increases immigrants' chances of employment across board. In terms of arrival cohorts, with the 1980s arrivals being the reference groups, all other arrival cohorts have negative effects to varying extent (pre-1980 Asian immigrants is an exception). The largest negative effects are found among the newest arrivals: those who arrive after 2000. This is consistent with assimilation theory and suggests that their limited time duration and experience in the U.S. hurts their employment prospects.

Given the dramatic decline in the economy between 2007 and 2009, the likelihood of employment for all groups is less in 2009 than 2007 - this effect is fairly consistent across 
groups, but is largest for Latino immigrants. Asians and Latinos, regardless of nativity, are worse off during this period than Whites, however, immigrants are more likely to be employed than natives during the study period between 2007 and 2009. A key finding of this paper is that immigrants as a whole experienced decreased likelihood of employment in 2009 compared with 2007 in a similar fashion to the native-born. And across all groups, the Latino immigrants are hit the hardest with the largest recession effects as shown by year 2009 variable.

For all groups, the Midwest shows a slight employment disadvantage, however much of this effect is largely due to the experience of the native-born. Looking at individuals separately reveals more nuanced regional variation for Asian and Latino immigrants with both groups faring better in the South and Latino immigrants faring worse in the Northeast as compared to the West. Also, states in which E-Verify was or was about to be adopted show a negative effect on employment likelihood of immigrant employment. Interestingly, this effect is significant for the Latino immigrants but not the Asian immigrants. So, whether due to unintended policy effects on authorized immigrants or negative perceptions conveyed to and about these Latino legal workers, the state-level activity surrounding E-Verify, albeit not necessarily the presence of E-Verify itself, appears to be hurting Latino immigrants.

Next, we take notice of the role of gateway type on immigrants' employment outcomes. High presence gateways (those with high percentage immigrants), especially high presence and low growth gateways, do not bode well for immigrants in general and Latino immigrants in particular as suggested by the negative significant effects. Contrary to what social networks arguments would imply, immigrants living in MSAs with high share of immigrants actually face greater challenges of finding jobs, all else equal. The traditional notions of ethnic enclaves and ethnic economies may be changing both as immigrants' location patterns change and the 
metropolitan characteristics immigrants respond to evolve. The competition among immigrants for the available jobs in these areas might outweigh the benefit of social networks. Last, MSA economy size is positive and significant, particularly for the full sample, all immigrants, and Latino immigrants.

\section{Robustness Checks}

We perform two individual regression robustness checks on MSA gateway categorization. The first involves re-running the models in Table 6 using continuous variables for immigrant presence and new arrival percentages; thus, instead of four dichotomous variable identifying gateway type, we included a single interaction term between the two continuous variables alongside each individual variable. For the entire population, neither the interaction term nor the percentage of MSA that is immigrant were significant; however, percent new arrivals was significant and positive, possibly indicating the strong attraction for newly arrived immigrants to areas with stronger economies or at least lower barriers to employment. To determine whether this effect is consistent across natives and immigrants, we also looked at each population group and found that this effect is consistent for the native-born and immigrants. Both population groups have increased likelihoods of employment for the combined years of the study period in areas in which the percentage of new arrival immigrants is high.

Since we showed discretion in the selection of the cutoff point for categorization of gateway types as high presence / high new arrival, high presence / low new arrival, low presence / high new arrival, low presence / low new arrival, we also ran the models in Table 6 using several different cutoff definitions in addition to the median values for the top 100 MSAs: 1) mean values for the top 100 MSAs, 2) median values for all 283 MSAs in the U.S., and 3) mean 
values for all 283 MSAs in the U.S. The results are fairly consistent, demonstrating the robustness of our results across some variability in gateway classification scheme.

\section{CONCLUSION AND DISCUSSION}

The Great Recession hit the U.S. economy at an unprecedented level in recent memory. While unemployment rose between 2007 and 2009, such increase is not uniform across population groups and across metropolitan areas. This paper compares the employment outcomes between immigrants and their native-born counterparts and also makes distinction among Asian and Latino immigrants to examine their experience through the Great Recession. It also pays particular attention to individual- and MSA-level factors that affect their economic performance. During these two years, while unemployment rates rose for all groups, Latino immigrants, especially low-skilled immigrants and female immigrants, are hit the hardest across all groups. The usual human capital attributes including skill level, experience and English proficiency still hold in securing employment during this period.

We are also interested in variations in terms of metropolitan context in shaping immigrants' employment outcomes. The fact that immigrants are moving away from established gateways and towards newer gateways is well-documented (Singer 2004; Lichter and Johnson 2009) and some have started to examine immigrants' success in these new destinations as compared to traditional destinations in the housing market (Painter and Yu, 2010) and the labor market (Hall, 2009). Our results indicate that immigrants' likelihood of employment is less in metropolitan areas with existing large share of immigrants, and particularly those with low recent immigrant growth. Even the native-born population fare worse in the high presence and low growth areas. Two explanations can possibly be offered for these findings. First, immigrants are 
in fact substitutes among themselves as evidenced elsewhere by their high level of occupational and industrial concentration or niching. Thus, high immigrant presence might lower employment prospects for all immigrants. Second, immigrants may be electing to locate in areas where barriers to economic entry are lower for all citizens, regardless of nativity, i.e. high growth areas (Baird et al, 2008).

Immigrants have historically relied upon social networks and ethnic resources in securing employment. Networks and channels of information drove much of immigrants' economic success during the middle and latter half of the twentieth century. Other research demonstrates that immigrant migration patterns are changing and ethnic enclaves are losing prominence relative to more general indicators of an area's economic prospects as signals for location decisions. Since we found that immigrants fared worse during the recession period in areas populated with a large percentage of immigrants, it seems to echo the evolving relationships between immigrants and the metropolitan areas that they live in.

Another interesting finding is the role of state immigration policy on immigrants' employment outcomes. The presence of E-Verify, operationalized as a state-level contextual measure of receptivity toward illegal immigrants in particular and immigrants in general, shows a negative effect on employment for immigrants but not the native-born and for Latino immigrants but not Asian immigrants. This possibly means that state activity associated with EVerify does in fact hurt immigrant employment. Mechanisms through which effect occurs is not clear in the current analysis and requires further examination.

As the U.S. recovers from the recession, the next important question is how immigrants recover from the recession period and what policy tools are available to aid immigrants in need. Unemployment insurance has many restrictions, making it ineffective for low-wage workers with 
nonstandard work arrangements: the self-employed, part-time work, and contingent employment. Many immigrant workers fall into these categories. They are in need of additional support in certain regions and metropolitan areas as a result of the Great Recession and arguably in the near future. 


\section{REFERENCES}

Akresh, I. R. (2007) U.S. immigrants' labor market adjustment: Additional human capital investment and earnings growth. Demography, 44(4), 865-881.

Aponte, R. (1996). Urban employment and the mismatch dilemma: Accounting for the immigration exception. Social Problems, 43 (3), 268-283.

Baird, J., R. Adelman, L. Reid, and C. Jaret (2008) Immigrant settlement patterns: The role of metropolitan characteristics. Sociological Inquiry, 78(3), 310-334.

Barth, E., Bratsberg, B., and Raaum, O. (2006) Local unemployment and the relative wages of immigrants: Evidence from the Current Population Surveys. Review of Economics and Statistics, $88,243-263$.

Borjas, G. (1999) The economic analysis of immigration. In Handbook of Labor Economics, Ed. 3, Part A, 1697-1760.

Borjas, G. J. (2001) Does immigration grease the wheels of the labor market? Brookings Papers on Economic Activity, 1: 69-119.

Burstein, P. (1998) Bringing the public back in: Should sociologists consider the impact of public opinion on public policy? Social Forces, 77(1), 27-62.

Cowan, Martinez, and Mendiola (1997) Predictors of attitudes toward illegal Latino immigrants. Hispanic Journal of Behavioral Sciences, 19(4), 403-415.

De Jong, G. F., and Steinmetz, M. (2004) Receptivity attitudes and the occupational attainment of male and female immigrant workers. Population Research and Policy Review, 23, 91-116.

Gurak, D. T. and M. M. Kritz. The interstate migration of U.S. immigrants: Individual and contextual determinants. Social forces 78 (3): 1017-1039.

Hall, M., A. singer, G. F. De Jong, and D. R. Graefe (2011) The geography of immigrant skills: educational profiles of metropolitan areas. Brookings Institute Metropolitan Policy Program, June 2011.

Kochhar, R., C. S. Espinoza and R. Hinze-Pifer (2010) After the great recession: Foreign born gain jobs; Native born lose jobs. Pew Hispanic Center Report, October 2010.

LaLonde, R. J., and Topel, R. H. (1991) Immigrants in the American labor market: Quality, assimilation, and distributional effects. The American Economic Review, 81(2), 297-302.

LawLogix (2012) E-Verify state rules. Retrieved from www.lawlogix.com 
Lichter, D. T. and K. M. Johnson (2009) Immigrant Gateways and Hispanic migration to new destinations. International Migration Review 43: 496-518.

Light, I. H. (2006) Deflecting immigration: Networks, markets, and regulation in Los Angeles. New York: Russell Sage Foundation.

Lofstrom, M., S. Bohn, and S. Raphael. (2011) Lessons from the 2007 Legal Arizona Workers Act. Public Policy Institute of California report, March 2011.

Masey, D. (2008) New faces in new places: The new geography of American Immigration. New York: Russell Sage Foundation.

Myers, D. (1999) Demographic dynamism and metropolitan change: Comparison of Los Angeles, New York, Chicago, and Washington, D.C. Housing Policy Debate 10: 919-955.

Ottaviano, G., and Peri, G. (2006) Rethinking the effects of immigration on wages. NBER Working Paper No. 12497

Orrenius, P. M. and M. Zavodny (2009) Tied to the business cycle: How immigrants fare in good and bad economic times? Migration Policy Institute, Washington, D.C. (November 2009).

Orrenius, P. and Zavodny, M. (2010) Immigrants' employment outcomes over the business cycle. IZA Dioscussion Paper No. 5354.

Orrenius, P. and M. Zavodny (2011) Immigrants' employment outcomes over the business cycle. Federal Reserve Bank of Dallas Staff Papers, No. 15, September 2011.

Painter, G. and Z. Yu. (2010) Immigrants and housing markets in mid-size metropolitan areas. International Migration Review 44 (2): 442-476.

Passel, J. S. and D Cohn (2010). U.S. unauthorized immigration flows are down sharply since mid-decade. Pew Hispanic Center report, October 2010.

Pearson-Merkowitz, S. (2011) Punitive immigration reform in the states: A test of four models. State Politics and Policy Conference 2011.

Peri, G. and C. Sparber. 2009. Task specialization, immigration and wages. American Economic Journal, Applied Economics 1(3): 135-69.

Ruggles, J., Alexander, J. T., Genadek, K., Goeken, R., Schorieder, M. B., and Sobek, M. (2010) Integrated Public Use Microdata Series: Version 5.0 [Machine-readable database'. Minneapolis: University of Minnesota.

Ryu, J. E., Bowling, C. J., Cho, C.-L., and Wright, D. S. (2008) Explanations of state agency budget: Institutional budget actors or exogenous environment? Public Budgeting \& Finance, 28(3), 23-47. 
Sahin, A., Song, J., and Jobijn, B. (2010) The unemployment gender gap during the current recession. Current Issues in Economics and Finance, 16(2), 1-7.

Singer, A., and J. H. Wilson (2010) The impact of the great recession on metropolitan immigration trends. Brookings Institute Metropolitan Policy Program, December 2010. Trejo, S. (1997) Why do Mexican americans earn low wages? Journal of Political Economy, 105(6), 1235-1268.

Waldinger, R. (1994) The making of an immigrant niche. International Migration Review 28 (1): 3-30.

Waldinger, R., \& C. Der-Martirosian (2001) The immigrant niche: Pervasive, persistent, diverse. In R. Waldinger (Ed.) Strangers at the gate: New immigrants in urban America (pp. 228-271). Berkeley and Los Angeles: University of California Press.

Wilson, J. H. and A. Singer (2011) Immigrants in 2010 metropolitan America: A decade of change. Brookings Institute Metropolitan Policy Program, October 2011. 
Table 1. Population and Growth for 100 MSAs and United States, 2005, 2007, and 2009

\begin{tabular}{|c|c|c|c|c|c|c|}
\hline & & $\begin{array}{c}\text { Total } \\
\text { Population }\end{array}$ & $\begin{array}{c}\text { Total } \\
\text { Immigrants }\end{array}$ & $\begin{array}{c}\text { Asian } \\
\text { Immigrants }\end{array}$ & $\begin{array}{c}\text { Latino } \\
\text { Immigrants }\end{array}$ & $\begin{array}{l}\text { Percentage } \\
\text { I mmigrants }\end{array}$ \\
\hline \multirow[t]{2}{*}{2005} & $100 \mathrm{MSA}$ & $181,391,511$ & $30,321,525$ & $7,553,643$ & $13,986,102$ & $16.7 \%$ \\
\hline & U.S. & $288,000,000$ & $35,800,000$ & $8,529,557$ & $16,800,000$ & $12.4 \%$ \\
\hline \multirow[t]{2}{*}{2007} & 100 MSA & $189,340,079$ & $31,949,996$ & $7,981,110$ & $14,839,711$ & $16.9 \%$ \\
\hline & U.S. & $302,000,000$ & $38,000,000$ & $9,102,212$ & $18,000,000$ & $12.6 \%$ \\
\hline \multirow[t]{2}{*}{2009} & 100 MSA & $193,361,362$ & $32,275,979$ & $8,208,260$ & $14,839,753$ & $16.7 \%$ \\
\hline & U.S. & $307,000,000$ & $38,500,000$ & $\begin{array}{c}9,358,989 \\
\text { Growth }\end{array}$ & $18,100,000$ & $12.5 \%$ \\
\hline \multirow[t]{2}{*}{ 2005-7 } & $100 \mathrm{MSA}$ & $7,948,568$ & $1,628,471$ & 427,467 & 853,609 & $5.4 \%$ \\
\hline & U.S. & $14,000,000$ & $2,200,000$ & 572,655 & $1,200,000$ & $6.2 \%$ \\
\hline \multirow[t]{2}{*}{ 2007-9 } & $100 \mathrm{MSA}$ & $4,021,283$ & 325,983 & 227,150 & 42 & $1.0 \%$ \\
\hline & U.S. & $5,000,000$ & 500,000 & 256,777 & 100,000 & $1.3 \%$ \\
\hline
\end{tabular}

Source: Authors' calculation of IPUMS data 
Table 2. Unemployment Rates for 100 MSAs and United States, 2005, 2007, 2009

\begin{tabular}{|c|c|c|c|c|c|c|c|c|c|}
\hline & & $\begin{array}{c}\text { Total } \\
\text { Popolation }\end{array}$ & $\begin{array}{l}\text { Total Native- } \\
\text { born }\end{array}$ & $\begin{array}{c}\text { Total } \\
\text { Immigrants }\end{array}$ & $\begin{array}{c}\text { Asian } \\
\text { s Immigrants }\end{array}$ & $\underset{\mathrm{S}}{\text { Immigrant }}$ & $\underset{\mathrm{s}}{\text { Immigrant }}$ & $\begin{array}{l}\text { Medium Skill } \\
\text { Immigrants }\end{array}$ & $\begin{array}{c}\text { Immigrant } \\
\mathrm{s}\end{array}$ \\
\hline \multirow{2}{*}{2005} & 100 MSA & 6.9 & 7.0 & 6.6 & 5.7 & 7.2 & 8.7 & 6.7 & 4.2 \\
\hline & U.S. & 6.9 & 7.0 & 6.7 & 5.6 & 7.5 & 8.9 & 6.7 & 4.2 \\
\hline \multirow[t]{2}{*}{2007} & $100 \mathrm{MSA}$ & 6.2 & 6.4 & 5.3 & 4.7 & 5.7 & 7.0 & 5.5 & 3.6 \\
\hline & U.S. & 6.3 & 6.5 & 5.5 & 4.7 & 5.9 & 7 & 5.7 & 3.6 \\
\hline \multirow[t]{3}{*}{2009} & 100 MSA & 10.0 & 10.2 & 9.3 & 7.5 & 10.4 & 11.8 & 9.9 & 6.3 \\
\hline & U.S. & 9.9 & 10.0 & 9.4 & 7.4 & 10.6 & 11.9 & 9.9 & 6.1 \\
\hline & & \multicolumn{8}{|c|}{ Change (percentage points) } \\
\hline \multirow[t]{2}{*}{ 2005-7 } & $100 \mathrm{MSA}$ & -0.7 & -0.6 & -1.3 & -1.0 & -1.5 & -1.7 & -1.2 & -0.6 \\
\hline & U.S. & -0.6 & -0.5 & -1.2 & -0.9 & -1.6 & -1.9 & -1.0 & -0.6 \\
\hline \multirow[t]{2}{*}{ 2007-9 } & $100 \mathrm{MSA}$ & 3.8 & 3.8 & 4.0 & 2.8 & 4.7 & 4.8 & 4.4 & 2.7 \\
\hline & U.S. & 3.6 & 3.5 & 3.9 & 2.7 & 4.7 & 4.9 & 4.2 & 2.5 \\
\hline
\end{tabular}

Source: Authors' calculation of IPUMS data 
Table 3. Population, Immigrants and Unemployment Rates for 100 MSAs by Gateway Type, 2007 and 2009

\begin{tabular}{|c|c|c|c|c|c|c|c|c|}
\hline \multirow{3}{*}{$\begin{array}{l}\text { Gateway Type } \\
\text { High Presence }\end{array}$} & \multirow{3}{*}{$\begin{array}{l}\text { Year } \\
2007\end{array}$} & \multicolumn{3}{|c|}{ Population } & \multicolumn{4}{|c|}{ Unemployment Rate } \\
\hline & & $\begin{array}{l}\text { Total } \\
\text { Population }\end{array}$ & $\begin{array}{l}\text { Percentage } \\
\text { Immigrants }\end{array}$ & $\begin{array}{l}\text { Percentage } \\
\text { Immigrants who } \\
\text { are new arrivals }\end{array}$ & $\begin{array}{l}\text { Total } \\
\text { Population }\end{array}$ & $\begin{array}{l}\text { Total } \\
\text { Immigrant } \\
\text { s }\end{array}$ & $\begin{array}{l}\text { Asian } \\
\text { Immigrants }\end{array}$ & $\begin{array}{l}\text { Latino } \\
\text { Immigrants }\end{array}$ \\
\hline & & 47200000 & $14.1 \%$ & $46.0 \%$ & 5.8 & 5.1 & 4.3 & 4.9 \\
\hline $\begin{array}{l}\text { High Growth } \\
\text { (18 MSAs) }\end{array}$ & 2009 & 48800000 & $14.0 \%$ & $40.6 \%$ & 9.6 & 9.4 & 7.7 & 10.4 \\
\hline High Presence & 2007 & 92100000 & $24.4 \%$ & $31.7 \%$ & 6.5 & 5.5 & 4.8 & 5.9 \\
\hline $\begin{array}{l}\text { Low Growth } \\
\text { ( } 32 \text { MSAs) }\end{array}$ & 2009 & 93500000 & $24.1 \%$ & $29.5 \%$ & 10.6 & 9.5 & 7.7 & 10.4 \\
\hline Low Presence & 2007 & 33000000 & $5.8 \%$ & $50.4 \%$ & 6.1 & 5.3 & 4.4 & 6.2 \\
\hline $\begin{array}{l}\text { High Growth } \\
\text { ( } 32 \text { MSAs) }\end{array}$ & 2009 & 33800000 & $6.0 \%$ & $45.4 \%$ & 9.3 & 8.4 & 5.5 & 10.7 \\
\hline Low Presence & 2007 & 17000000 & $5.1 \%$ & $38.0 \%$ & 6.2 & 4.7 & 5.2 & 4.9 \\
\hline $\begin{array}{l}\text { Low Growth } \\
\text { (18 MSAs) }\end{array}$ & 2009 & 17300000 & $5.3 \%$ & $37.8 \%$ & 9.5 & 7.8 & 6 & 9.9 \\
\hline
\end{tabular}

Source: Authors' calculation of IPUMS data

Note: High or low presence is determined by percentage immigrants of all population above or below $8.47 \%$;

High or low growth is determined by percentage new arrivals (within last 10 years) of all immigrants above or below $41.45 \%$. 
Table 4. Population, Immigrants and Unemployment Rates for 100 MSAs by Region, 2007 and 2009

\begin{tabular}{|c|c|c|c|c|c|c|c|c|}
\hline \multirow{4}{*}{$\begin{array}{l}\text { Region } \\
\text { Northeast } \\
\text { (16 MSAs) }\end{array}$} & \multirow{4}{*}{$\begin{array}{l}\text { Year } \\
2007 \\
2009\end{array}$} & \multicolumn{3}{|c|}{ Population } & \multicolumn{4}{|c|}{ Unemployment Rate } \\
\hline & & Total Population & $\begin{array}{l}\text { Percentage } \\
\text { Immigrants }\end{array}$ & $\begin{array}{l}\text { Percentage } \\
\text { Immigrants who } \\
\text { are new arrivals }\end{array}$ & $\begin{array}{l}\text { Total } \\
\text { Population }\end{array}$ & $\begin{array}{l}\text { Total } \\
\text { Immigrant } \\
\mathrm{s}\end{array}$ & $\begin{array}{l}\text { Asian } \\
\text { Immigrants }\end{array}$ & $\begin{array}{l}\text { Latino } \\
\text { Immigrants }\end{array}$ \\
\hline & & 38800000 & $18.5 \%$ & $33.8 \%$ & 6 & 5.5 & 4.8 & 6.5 \\
\hline & & 39400000 & $18.2 \%$ & $32.8 \%$ & 9.2 & 8.6 & 7.4 & 9.7 \\
\hline Midwest & 2007 & 36000000 & $9.3 \%$ & $40.2 \%$ & 7.2 & 5.8 & 4.7 & 6.3 \\
\hline (40 MSAs) & 2009 & 36300000 & $9.2 \%$ & $35.4 \%$ & 10.9 & 10.1 & 8 & 11 \\
\hline South & 2007 & 62300000 & $14.7 \%$ & $42.4 \%$ & 6 & 5.1 & 4.2 & 5.1 \\
\hline (20 MSAs) & 2009 & 64400000 & $14.8 \%$ & $38.8 \%$ & 9.6 & 9 & 6.5 & 9.7 \\
\hline West & 2007 & 51500000 & $23.5 \%$ & $31.4 \%$ & 6 & 5.4 & 4.9 & 5.8 \\
\hline (24 MSAs) & 2009 & 52600000 & $22.9 \%$ & $28.1 \%$ & 10.6 & 9.9 & 8 & 11.1 \\
\hline
\end{tabular}

Source: Authors' calculation of IPUMS data 
Table 5. Independent Variables and Mean Statistics (2007 and 2009 combined sample)

\begin{tabular}{|c|c|c|c|c|c|}
\hline & Full sample & Native-born & $\begin{array}{l}\text { All } \\
\text { I mmigrants }\end{array}$ & $\begin{array}{l}\text { Asian } \\
\text { Immigrants }\end{array}$ & $\begin{array}{l}\text { Latino } \\
\text { Immigrants }\end{array}$ \\
\hline \multicolumn{6}{|l|}{ I ndividual Variables } \\
\hline Female & 0.468 & 0.481 & 0.415 & 0.468 & 0.365 \\
\hline Married & 0.517 & 0.493 & 0.61 & 0.711 & 0.561 \\
\hline Has child(ren) & 0.414 & 0.388 & 0.512 & 0.54 & 0.523 \\
\hline Low-Skill (Highschool dropout) & 0.121 & 0.08 & 0.274 & 0.107 & 0.457 \\
\hline Medium-Skill (Highschool grad) & 0.551 & 0.582 & 0.436 & 0.361 & 0.437 \\
\hline High-Skill (College and above) & 0.328 & 0.338 & 0.29 & 0.533 & 0.106 \\
\hline Speaks English & . & . & 0.717 & 0.841 & 0.541 \\
\hline pre-1980 Arrival Cohort & . & . & 0.182 & 0.17 & 0.158 \\
\hline 1980s Arrival Cohort & . & . & 0.244 & 0.278 & 0.246 \\
\hline 1990s Arrival Cohort & . & . & 0.312 & 0.31 & 0.317 \\
\hline 2000s Arrival Cohort & . & . & 0.261 & 0.242 & 0.279 \\
\hline Hispanic & 0.179 & 0.099 & 0.483 & . & . \\
\hline Non-Hispanic Asian & 0.069 & 0.021 & 0.25 & . & . \\
\hline Non-Hispanic Black & 0.137 & 0.15 & 0.089 & . & . \\
\hline Non-Hispanic White & 0.615 & 0.73 & 0.178 & . & . \\
\hline Age & 40.63 & 40.612 & 40.697 & 42.161 & 38.609 \\
\hline Year 2009 & 0.509 & 0.508 & 0.511 & 0.516 & 0.508 \\
\hline \multicolumn{6}{|l|}{ MSA Variables } \\
\hline \multicolumn{6}{|l|}{ Region } \\
\hline West & 0.266 & 0.238 & 0.373 & 0.451 & 0.417 \\
\hline South & 0.335 & 0.344 & 0.301 & 0.217 & 0.351 \\
\hline Midwest & 0.193 & 0.217 & 0.104 & 0.108 & 0.084 \\
\hline Northeast & 0.206 & 0.201 & 0.222 & 0.224 & 0.148 \\
\hline Has E-verify & 0.318 & 0.34 & 0.234 & 0.168 & 0.255 \\
\hline \multicolumn{6}{|l|}{ Gateway type } \\
\hline High presence / High Growth & 0.258 & 0.269 & 0.217 & 0.209 & 0.215 \\
\hline High presence / Low growth & 0.477 & 0.418 & 0.697 & 0.689 & 0.725 \\
\hline Low presence / High growth & 0.177 & 0.208 & 0.061 & 0.07 & 0.047 \\
\hline Low presence / Low growth & 0.088 & 0.105 & 0.025 & 0.032 & 0.013 \\
\hline MSA Total Employment 2007 & 2423049 & 2164688 & 3402930 & 3402388 & 3255806 \\
\hline $\mathrm{N}$ & $1,779,939$ & $1,444,388$ & 335,551 & 95,627 & 146,535 \\
\hline
\end{tabular}

Source: Authors' calculation of IPUMS data 
Asian

Latino

Constant

\section{I ndividual Variables}

Female

Married

Has child(ren)

Low Skill

Medium Skill

Immigrant

Immigrant $x$ Speaks English

Immigrant $x$ Cohort

pre- 1980

1990s

2000s

Hispanic

Non-Hispanic Asian

Non-Hispanic Black

Age

Year 2009

Immigrant x year 2009

\section{MSA Variables}

Region (reference: West)

South

Midwest

Northeast

E-verify

High presence / High growth High presence / Low growth

Low presence / High growth

MSA Total Employment in 2007

\section{N \\ Log likelihood}

Clusters

\begin{tabular}{|c|c|c|c|c|}
\hline All & Native-born & Immigrants & Immigrants & Immigrants \\
\hline $1.452 * * *$ & $1.448 * * *$ & $1.589 * * *$ & $1.580 * * *$ & $1.585 * * *$ \\
\hline $.047 * * *$ & $.089 * * *$ & $-.121 * * *$ & $-.044 * * *$ & $-.229 * * *$ \\
\hline $.245 * * *$ & $.280 * * *$ & $.095 * * *$ & $.171 * * *$ & $.052 * * *$ \\
\hline $.079 * * *$ & $.085 * * *$ & $.054 * * *$ & $.059 * * *$ & $.057 * * *$ \\
\hline$-.657 * * *$ & $-.766 * * *$ & $-.311 * * *$ & $-.320 * * *$ & $-.277 * * *$ \\
\hline$-.306 * * *$ & $-.330 * * *$ & $-.188 * * *$ & $-.216 * * *$ & $-.154 * * *$ \\
\hline $.125 * * *$ & 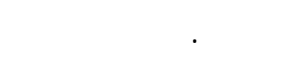 & & & \\
\hline-.002 & . & $.110 * * *$ & $.122 * * *$ & $.095 * * *$ \\
\hline$-.064 * * *$ & . & -.007 & $.038 *$ & -.012 \\
\hline-.009 & . & $-.027 * * *$ & -.026 & -.018 \\
\hline$-.075 * * *$ & . & $-.112 * * *$ & $-.189 * * *$ & $-.074 * * *$ \\
\hline$-.052 * * *$ & $-.085 * * *$ & -.003 & . & . \\
\hline$-.092 * * *$ & .003 & .014 & . & . \\
\hline$-.317 * * *$ & $-.324 * * *$ & $-.162 * * *$ & . & · \\
\hline $.008 * * *$ & $.008 * * *$ & $.004 * * *$ & $.001 * *$ & $.005 * * *$ \\
\hline$-.268 * * *$ & $-.272 * * *$ & $-.271 * * *$ & $-.207 * * *$ & $-.307 * * *$ \\
\hline-.019 & . & 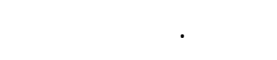 & . & · \\
\hline .043 & .042 & $.082 * * *$ & $.066 * *$ & $.105 * * *$ \\
\hline$-.064 *$ & $-.061 *$ & -.040 & -.032 & -.043 \\
\hline .002 & .009 & -.005 & .004 & $-.067 * *$ \\
\hline-.016 & -.007 & $-.054 * * *$ & -.001 & $-.065 * * *$ \\
\hline-.041 & -.039 & $-.076 * *$ & -.062 & -.068 \\
\hline$-.119 * * *$ & $-.112 * * *$ & $-.140 * * *$ & $-.095 * *$ & $-.136 * *$ \\
\hline .014 & .013 & -.024 & .039 & -.031 \\
\hline $.000 * * *$ & .000 & $.000 * * *$ & .000 & $.000 * * *$ \\
\hline $1,779,939$ & $1,444,388$ & 335,551 & 95,627 & 146,535 \\
\hline-444259.2 & -355885.6 & -86253.6 & -21327.5 & -41735.3 \\
\hline 100 & 100 & 100 & 100 & 100 \\
\hline
\end{tabular}

$* \mathrm{p}<.1, * * \mathrm{p}<.05, * * * \mathrm{p}<.01$. Significance levels are determined using robust standard errors with MSA clusters. 
Appendix A. States with E-Verify requirements and/or voluntary availability as of 2012

\begin{tabular}{lc}
\hline State & Year of First Adoption \\
Alabama & 2012 \\
Arizona & 2008 \\
Colorado & 2006 \\
Florida & 2011 \\
Georgia & 2012 \\
Illinois & 2010 \\
Idaho & 2009 \\
Indiana & 2011 \\
Louisiana & 2011 \\
Minnesota & 2011 \\
Mississippi & 2008 \\
Missouri & 2009 \\
Nebraska & 2009 \\
North Carolina & 2007 \\
Oklahoma & 2007 \\
South Carolina & 2009 \\
Tennessee & 2012 \\
Utah & 2009 \\
Virginia & 2012 \\
\hline
\end{tabular}

Source: LawLogix (www.lawlogix.com); National Association of Government Contractors 
I mmigrant low growth ( $\mathrm{N}=\mathbf{5 0})$

\begin{tabular}{|c|c|c|c|}
\hline (2) & Wichita, KS & Ann Arbor, MI & Lancaster, PA \\
\hline Albany-Schenectady-Troy, NY & Youngstown-Warren, OH-PA & Baltimore, MD & Little Rock--North Little Rock, AR \\
\hline Allentown-Bethlehem-Easton, PA/NJ & & Birmingham, AL & Louisville, KY/IN \\
\hline Augusta-Aiken, GA-SC & & Charleston-N.Charleston,SC & Madison, WI \\
\hline Baton Rouge, LA & & Cincinnati-Hamilton, $\mathrm{OH} / \mathrm{KY} / \mathrm{IN}$ & VMemphis, TN/AR/MS \\
\hline Boise City, ID & & Colorado Springs, CO & Milwaukee, WI \\
\hline Buffalo-Niagara Falls, NY & & Columbia, SC & Mobile, AL \\
\hline Cleveland, $\mathrm{OH}$ & & Columbus, $\mathrm{OH}$ & Nashville, TN \\
\hline Dayton-Springfield, $\mathrm{OH}$ & & Grand Rapids, MI & Omaha, NE/IA \\
\hline Daytona Beach, FL & & Greensboro-Winston Salem- $\mathrm{Hi}$ & i! Provo-Orem, UT \\
\hline New Orleans, LA & & Greenville-Spartanburg-Anders & Richmond-Petersburg, VA \\
\hline Norfolk-VA Beach--Newport News, VA & & Harrisburg-Lebanon--Carlisle, & St. Louis, MO-IL \\
\hline Pittsburgh, PA & & Indianapolis, IN & Syracuse, NY \\
\hline Rochester, NY & & Jacksonville, FL & Toledo, $\mathrm{OH} / \mathrm{MI}$ \\
\hline Scranton-Wilkes-Barre, PA & & Kansas City, MO-KS & Tulsa, OK \\
\hline Tacoma, WA & & Knoxville, TN & Wilmington, $\mathrm{DE} / \mathrm{NJ} / \mathrm{MD}$ \\
\hline Albuquerque, NM & Modesto, CA & Atlanta, GA & Tampa-St. Petersburg-Clearwater, FL \\
\hline Bakersfield, CA & Monmouth-Ocean, NJ & Austin, TX & Washington, $\mathrm{DC} / \mathrm{MD} / \mathrm{VA}$ \\
\hline Boston, MA-NH & New York-Northeastern NJ & Charlotte-Gastonia-Rock Hill, N & NC-SC \\
\hline Chicago, IL & Portland, OR-WA & Dallas-Fort Worth, TX & \\
\hline Detroit, MI & Providence-Fall River-Pawtucket, MA/RI & Denver-Boulder, CO & \\
\hline El Paso, TX & Riverside-San Bernardino,CA & Fort Myers-Cape Coral, FL & \\
\hline Fort Lauderdale-Hollywood-Pompano Beach, & F Sacramento, CA & Lakeland-Winterhaven, FL & \\
\hline Fresno, CA & San Antonio, TX & Minneapolis-St. Paul, MN & \\
\hline Hartford-Bristol-Middleton- New Britain, CT & San Diego, CA & Oklahoma City, OK & \\
\hline Honolulu, HI & San Francisco-Oakland-Vallejo, CA & Orlando, FL & \\
\hline Houston-Brazoria, TX & San Jose, CA & Philadelphia, PA/NJ & \\
\hline Las Vegas, NV & Sarasota, FL & Phoenix, AZ & \\
\hline Los Angeles-Lor & Stockton, CA & Raleigh-Durham, NC & \\
\hline McAllen-Edinburg-Pharr-Mission, TX & Tucson, AZ & Salt Lake City-Ogden, UT & \\
\hline Melbourne-Titusville-Cocoa-Palm Bay, FL & Ventura-Oxnard-Simi Valley, CA & Seattle-Everett, WA & \\
\hline Miami-Hialeah, FL & West Palm Beach-Boca Raton-Delra & Springfield-Holyoke-Chicope & \\
\hline
\end{tabular}

I mmigrant high

presence

$(\mathrm{N}=\mathbf{5 0})$
Immigrant $(\mathrm{N}=\mathbf{5 0})$

Miami-Hialeah, FL

\section{Immigrant high growth ( $\mathrm{N}=\mathbf{5 0}$}

Birmingham, A

Cincinnati-Hamilton, OH/KY/INMemphis, TN/AR/MS

Greenville-Spartanburg-Anders Richmond-Petersburg, VA

on--Carlisle, St. Louis, MO-IL

New York-Northeastern $\mathrm{N}$

Portland, OR-WA

Mneapolis-St. Paul, MN

klahoma City, OK

Phoenix, AZ 